\title{
Wallet Pack Dosage Form
}

National Cancer Institute

\section{Source}

National Cancer Institute. Wallet Pack Dosage Form. NCI Thesaurus. Code C128665.

A multi-panel, re-closable end-user pack for tablet blisters. 